\title{
Chemical and spectroscopic characterization of insoluble and soluble humic acid fractions at different $\mathrm{pH}$ values
}

\author{
Andrea Baglieri ${ }^{*}$, Daniela Vindrola ${ }^{2}$, Mara Gennari ${ }^{1}$ and Michèle Negre ${ }^{2}$
}

\begin{abstract}
Background: Humic acids (HA) are organic molecules with complex structure and function and variable properties. They are insoluble in strongly acid pH conditions. At present, it is not clear how much is the amount of HA in solution at the $\mathrm{pH}$ of natural soils nor are known the characteristics of the different soluble fractions and their possible association with the inorganic phase of soil. The scope of this work was to characterize the soluble and insoluble fractions obtained by acidifying $\mathrm{Na}$ humate solution at $\mathrm{pH}$ values 3, 5, and 7 and to compare these fractions with the $\mathrm{HA}$ obtained at $\mathrm{pH}$ 1. At each $\mathrm{pH}$, the precipitate and the soluble fractions were separated and characterized by elemental analysis, total acidity and carboxylic group content, infrared, and ${ }^{13} \mathrm{C}$ NMR and ${ }^{1} \mathrm{H}$ NMR spectroscopy.

Results: The HA fraction insoluble at pH 1 had a high acid group content and aromaticity but a low content of Oand $\mathrm{N}$-containing groups. At pH 3, a fraction with nearly the same characteristics was obtained. At pH 1 and pH 3, the inorganic phase bound to the insoluble humic material was largely constituted by clay minerals and some Al and Fe hydroxides. The soluble fractions at pH values 1 and 3 were very poor and they were composed of a silica gel-like phase associated with polar organic material rich in carboxylic and metal-carboxylate groups. At pH values 5 and 7, only a small fraction of the Na humates precipitated. The fractions remaining in the solution were mainly composed of organic material particularly rich in aromatic and aliphatic groups, while the inorganic phase contained phyllosilicates. The fractions insoluble at pH values 5 and 7 contained a large amount of inorganic material that consisted mainly of phyllosilicates.

Conclusions: The soluble fractions obtained at $\mathrm{pH}$ values 5 and 7 represent the humic component that in environmental situations would be dissolved in the soil solution. Our findings could be very useful for a more detailed investigation into the way HA influence plant metabolism under environmental-like conditions, both as regards $\mathrm{pH}$ conditions and interaction with the mineral fraction.
\end{abstract}

Keywords: Acid; $\mathrm{pH}$; Mineral component; ${ }^{13} \mathrm{C}$ NMR; FT-IR; Humic fraction

\section{Background}

Soil organic matter can be divided into two major components: organic substances of an individual nature and humic substances (HS). Traditionally, the soil HS have been subdivided into three fractions: fulvic acids, humic acids (HA), and humin.

It is widely recognized that HS are important for the sustainability of terrestrial life. The heterogeneous

\footnotetext{
* Correspondence: abaglie@unict.it

'Dipartimento di Scienze delle Produzioni Agrarie e Alimentari, University of Catania, Via S. Sofia 98, 95123 Catania (CT), Italy

Full list of author information is available at the end of the article
}

chemical nature of HS exerts a multifunctional role in the environment by controlling the biogeochemical carbon cycle [1,2], providing nutrients and bio-stimulants for plant growth [3,4], and interacting with inorganic [5] and organic pollutants $[6,7]$.

It is common knowledge that the characteristics of $\mathrm{HS}$ depend on the extraction procedure adopted. This fact has been attributed to the complex nature of soil, to the wide range of physical and chemical properties inherent in humic material, and in particular to the intimate association of organic and inorganic soil constituents [8]. Most of the studies reporting the effect of extraction procedures 
on the chemical structure of HS have concerned the nature of the extraction solvent. These studies pointed out that both the type of soil and the extraction $\mathrm{pH}$ played a role in the chemical structure and molecular weight of the humic materials. The procedure recommended by the International Humic Substances Society (IHSS) for preparing HA [9] includes $0.1 \mathrm{M}$ sodium hydroxide extraction followed by $0.1 \mathrm{M}$ hydrochloric acid precipitation. In accordance with the new concept of supramolecular association, the HA obtained by this procedure is composed of many relatively small, chemically diverse organic molecules which form clusters linked by hydrogen bonds (H-bonds) and hydrophobic interactions [10]. A corollary to this model is the concept of micellar structure, i.e., an arrangement of organic molecules in aqueous solution which form hydrophilic exterior regions that shield the hydrophobic interiors from contact with vicinal water molecules [11].

It is assumed that humic acids are completely soluble at $\mathrm{pH} 13$ and completely insoluble at $\mathrm{pH} \mathrm{1,} \mathrm{but} \mathrm{the} \mathrm{solu-}$ bility of $\mathrm{HA}$ at intermediate $\mathrm{pH}$ values has not been fully investigated. Brigante et al. [12] measured the dissolution kinetics of HA prepared according to the IHSS procedure at different $\mathrm{pH}$ values between 10 and 4 . HA were completely soluble within less than an hour at $\mathrm{pH}>10$. At $\mathrm{pH}$ between 10 and 9, the dissolution was slower but nearly complete. At pH 8.5 and 8, more than 60\% and $40 \%$ of the HA respectively were soluble. The separation of HA in a soluble and an insoluble phase at these $\mathrm{pH}$ values attests for the heterogeneity of the material defined as humic acid on the basis of its insolubility at $\mathrm{pH} 1$. At our knowledge, the chemical differences between the soluble and insoluble fractions at a given $\mathrm{pH}$ have not been investigated.

A drawback of the IHSS procedure is that the HA may contain quite large amounts (e.g., 30\%) of inorganic components. Although some attempts have been made to destroy the organo-mineral associations before HS extraction $[13,14]$, a purification procedure aimed at obtaining ash-free organic fractions is commonly carried out on the extracted humic materials.

Such purification procedure, based on hydrochlorichydrofluoric acid solubilization of the inorganic fraction, generally decreases the ash content to less than $2 \%$. This is considered a good result as far as the purity of the humic material is concerned. However, little attention has been given to the nature of the inorganic fraction brought in solution by the alkaline extraction and so strongly bound to the humic material to require a drastic treatment to be released.

In this study, a $\mathrm{Na}$ humate solution was prepared following the IHSS procedure but without treatment to eliminate the inorganic phase. Aliquots of the humate solution were brought to $\mathrm{pH} 7,5,3$, and 1 , and the corresponding soluble and insoluble fractions were collected and characterized. The scope was to determine the chemical structure of the organic and inorganic materials precipitated or left in solution at each $\mathrm{pH}$ and to obtain some elucidation on the nature of their interactions.

\section{Experimental Materials \\ Soil}

The HA was extracted from a histosol (Trana, Turin, Italy), studied in another article [15], having the following properties: $\mathrm{pH}, 6.9$; clay, 5.7\%; loam, 30.5\%; sand, 63.8\%; organic carbon, $8.51 \%$; cation exchange capacity, $52.9 \mathrm{meq} / 100 \mathrm{~g} ; \mathrm{Na}$ oxalate extractable $\mathrm{Fe}, 0.68 \%$; $\mathrm{Na}$ dithionite-citrate-bicarbonate extractable Fe, 0.86\%; and Na pyrophosphate extractable Fe, $0.22 \%$.

\section{Methods}

\section{Preparation of the HA fractions}

The soil (100 g subsamples in $500 \mathrm{ml}$ PE flasks) was equilibrated to a $\mathrm{pH}$ value of between 1 and 2 with $1 \mathrm{M} \mathrm{HCl}$; the suspension was brought to $500 \mathrm{ml}$ with $0.1 \mathrm{M} \mathrm{HCl}$, shaken for $1 \mathrm{~h}$, centrifuged, and the supernatant eliminated. The solid phase was neutralized to $\mathrm{pH} 7$ with $1 \mathrm{M}$ $\mathrm{NaOH}$, then $0.1 \mathrm{M} \mathrm{NaOH}$ was added to provide a final volume of $500 \mathrm{ml}$. The suspension was shaken under $\mathrm{N}_{2}$ for $20 \mathrm{~h}$, allowed to settle overnight, then centrifuged $(1,500 \mathrm{~g}, 30 \mathrm{~min})$ to separate the supernatant. A series of three alternate treatments with $0.1 \mathrm{M} \mathrm{HCl}$ and $0.1 \mathrm{M}$ $\mathrm{NaOH}$ was performed to solubilize and remove the fulvic acids. After the final treatment, the precipitate resulting from acidification was dissolved in $0.1 \mathrm{M} \mathrm{NaOH}$, and the whole was treated as illustrated in Figure 1. Equal parts of $\mathrm{Na}$ humate were acidified with $0.1 \mathrm{HCl} \mathrm{M}$ at different $\mathrm{pH}$ values, 1, 3, 5, and 7. At each $\mathrm{pH}$, the soluble and insoluble fractions were separated by centrifugation. Subsequently, the fractions were dialyzed (MW cut-off 3,500 Da) and then freeze-dried.

\section{Characterization of the HA fractions}

The HA fractions were characterized for total acidity and carboxylic group content in accordance with the procedure proposed by Swift [9]; measurement of the phenol $\mathrm{OH}$ was obtained by difference; the $\mathrm{C}, \mathrm{H}, \mathrm{N}$ content was determined using a $\mathrm{C}, \mathrm{H}$, and N LECO Analyzer model 600 (LECO Corp., St. Joseph, MI, USA); O content was calculated by difference. Ash content was determined by incineration at $650^{\circ} \mathrm{C}$ for $4 \mathrm{~h}$.

The FT-IR spectra were obtained with a Perkin-Elmer FT-IR 2000 spectrometer (Perkin Elmer Italia, S.p.A, Milan, Italy), equipped with an IR source, $\mathrm{KBr}$ beam splitter and DTGS $\mathrm{KBr}$ detector. For each sample, 64 scans were recorded with a $4-\mathrm{cm}^{-1}$ resolution over a 4,000 


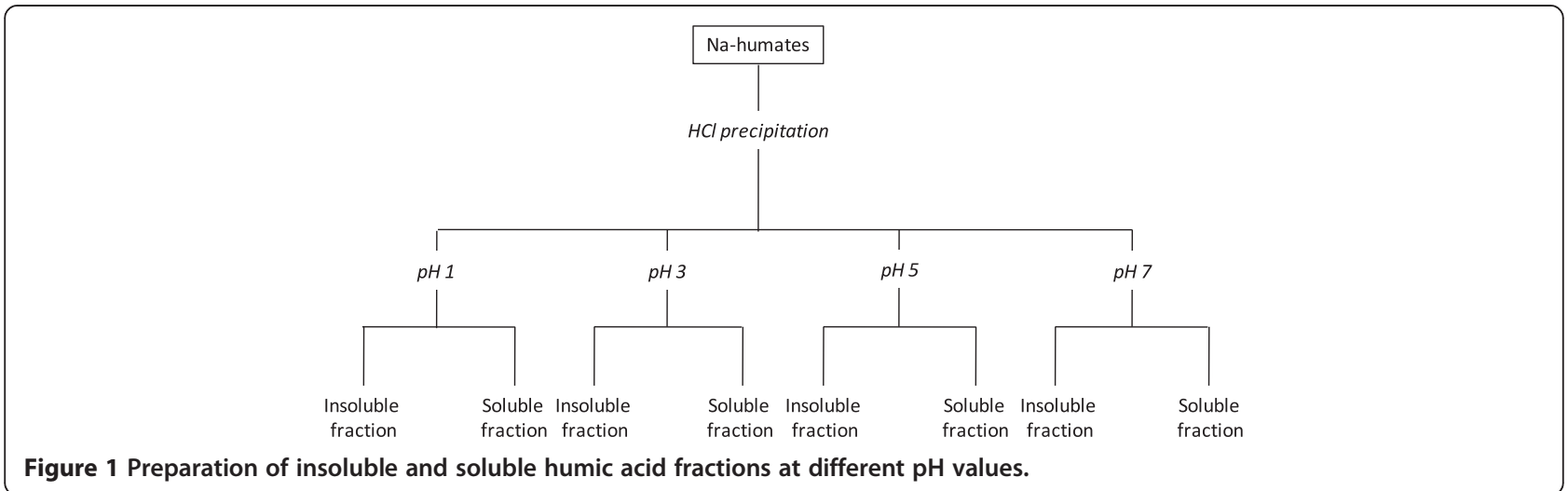

to $400 \mathrm{~cm}^{-1}$ range on pellets obtained by pressing a mixture of $1 \mathrm{mg}$ organic sample and $400 \mathrm{mg}$ dried $\mathrm{KBr}$.

Solid-state ${ }^{13} \mathrm{C}$ MAS NMR spectra were recorded, fully proton-decoupled, on a Bruker MSL 200 NMR (Bruker Corp., The Woodlands, TX, USA) instrument operating at $50.3 \mathrm{MHz}$. Rotors with a $7-\mathrm{mm}$ diameter were filled with about $50 \mathrm{mg}$ of the sample; the spinning rate was $4,000 \mathrm{~Hz} \mathrm{~s}^{-1}$. The following experimental parameters were adopted: spectral width $20,000 \mathrm{~Hz}$, data points $2 \mathrm{~K}$, 100,000 scans, $4 \mu \mathrm{s}, 90$ degrees of excitation pulse, and 4 $s$ of relaxation delay. The HPDEC pulse sequence was used with a decoupling power of $300 \mathrm{~W}(9 \mathrm{H})$. The FID were zero-filled and processed with $5 \mathrm{~Hz}$ line broadening. Chemical shifts refer to ${ }^{13} \mathrm{CO}$ of glycine, set at $176.03 \mathrm{ppm}$.

The ${ }^{1} \mathrm{H}$ NMR spectra were recorded using a JEOL EX-400 spectrometer (JEOL, Peabody, MA, USA) equipped with a $5 \mathrm{~mL}$ probe operating at $399.78 \mathrm{MHz}$. Samples were prepared by dissolving $20 \mathrm{mg}$ of the sample in $0.6 \mathrm{~mL}$ of $0.1 \mathrm{M} \mathrm{NaOD} / \mathrm{D}_{2} \mathrm{O}$. After filtration through a glass wool filter, the samples were placed in NMR tubes for analysis. All the samples were adjusted to $\mathrm{pH} 12$. The ${ }^{1} \mathrm{H}$ NMR spectra were recorded using the presaturation sequence for selective saturation of the HDO resonance [16]. The main NMR parameters were $45^{\circ}$ pulse width, pre-irradiation
$10 \mathrm{~s}$, acquisition time $5.46 \mathrm{~s}$, and 64 scans for a total acquisition time of about $16 \mathrm{~min}$.

The iron and aluminum oxide contents were evaluated by $\mathrm{Na}$ dithionite-citrate-bicarbonate extraction [17] at $25^{\circ} \mathrm{C}$ (Fe DCB and $\mathrm{Al}$ DCB, respectively). Aqua regia was used to attack the metals, and then the total iron and aluminum in the humic fractions were analyzed.

All chemicals were of analytical grade, and three replicates per analytical determination were carried out.

Analytical data were evaluated by one-way ANOVA $(P<0.005)$ followed by the Tukey's test for multiple comparison procedures.

\section{Results}

\section{Yield and ash content}

The yield, ash content, and elemental composition of the humic fractions at each $\mathrm{pH}$ are reported in Table 1.

As expected, the yield of the insoluble fractions decreased as $\mathrm{pH}$ increased, while the contrary occurred for the soluble fractions. The total humic material (soluble + insoluble) extracted at each $\mathrm{pH}$ was not about the same (86.2, 95.2, 82.5,

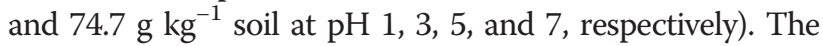
observed differences, in particular the low total recovery at $\mathrm{pH} 7$, suggest some loss of material, probably inorganic and

Table 1 Yield, ash content, and elemental composition of the humic fractions

\begin{tabular}{|c|c|c|c|c|c|c|c|c|}
\hline \multirow[t]{2}{*}{ Fraction } & & \multirow{2}{*}{$\begin{array}{l}\text { Yield } \\
\text { (g kg }^{-1} \text { soil) }\end{array}$} & \multirow{2}{*}{$\begin{array}{l}\mathrm{Ash}^{\mathrm{a}}\left(\mathrm{g} \mathrm{kg}^{-1}\right. \\
\text { humic fraction) }\end{array}$} & \multicolumn{4}{|c|}{ Elemental composition ${ }^{\mathbf{b}}\left(\mathrm{g} \mathrm{kg}^{-1}\right.$ humic fraction) } & \multirow{2}{*}{$\begin{array}{l}\text { Molar ratio } \\
\mathrm{O} / \mathrm{C}\end{array}$} \\
\hline & & & & $\mathrm{C}$ & $\mathrm{H}$ & $\mathbf{N}$ & 0 & \\
\hline \multirow[t]{2}{*}{ pH 1} & Insoluble & 83.9 & 247 & $541^{a}$ & $42^{\mathrm{a}}$ & $43^{\mathrm{a}}$ & $374^{\mathrm{a}}$ & 0.5 \\
\hline & Soluble & 2.3 & 196 & $478^{b d}$ & $44^{\mathrm{a}}$ & $43^{\mathrm{a}}$ & $434^{\mathrm{bc}}$ & 0.7 \\
\hline \multirow[t]{2}{*}{$\mathrm{pH} 3$} & Insoluble & 88.0 & 267 & $525^{\mathrm{a}}$ & $45^{\mathrm{a}}$ & $42^{\mathrm{a}}$ & $388^{\mathrm{ab}}$ & 0.5 \\
\hline & Soluble & 7.2 & 127 & $493^{\mathrm{bc}}$ & $41^{\mathrm{a}}$ & $45^{\mathrm{a}}$ & $421^{\mathrm{abc}}$ & 0.6 \\
\hline \multirow[t]{2}{*}{ pH 5} & Insoluble & 22.2 & 542 & $478^{\mathrm{bd}}$ & $55^{\mathrm{b}}$ & $40^{\mathrm{a}}$ & $427^{\mathrm{bc}}$ & 0.7 \\
\hline & Soluble & 60.3 & 225 & $518^{\mathrm{ac}}$ & $49^{\mathrm{b}}$ & $41^{a}$ & $392^{a b}$ & 0.6 \\
\hline \multirow[t]{2}{*}{ pH 7} & Insoluble & 7.4 & 609 & $451^{d}$ & $52^{\mathrm{b}}$ & $39^{\mathrm{a}}$ & $459^{c}$ & 0.8 \\
\hline & Soluble & 67.3 & 283 & $534^{a}$ & $49^{\mathrm{b}}$ & $42^{\mathrm{a}}$ & $375^{a}$ & 0.5 \\
\hline
\end{tabular}

${ }^{\mathrm{a} V a l u e s}$ are the means of three replicates, and the standard error values are $<10 \%$; ${ }^{\mathrm{b}}$ on a moisture and ash-free basis. Within columns, values followed by the same letter are not significantly different $(P<0.05)$. 
organic molecules smaller than the dialysis membrane MW cut-off.

The sum of the ash content of the soluble and insoluble fractions is not the same at each $\mathrm{pH}$. However, this difference is only apparent when considering the value corrected by the yield $(21.2,24.5,25.6$, and $23.6 \mathrm{~g}$ at $\mathrm{pH} 1$, 3,5 , and 7 respectively, for extracts from $1 \mathrm{~kg}$ of soil). This is demonstrated by the following calculation:

Gram of ash at each $\mathrm{pH}=\left(\right.$ Yeld IF $\left.\times \frac{\% \mathrm{IF} \text { ash }}{100}\right)+\left(\right.$ Yeld SF $\left.\times \frac{\% \mathrm{SF} \text { ash }}{100}\right)$

where IF is the insoluble fraction and SF is the soluble fraction.

The high ash content in all fractions emphasizes the importance of employing a purification step if ash-free humic fractions are to be obtained. The effectiveness of the purification step in HA prepared from a histosol was demonstrated by Piccolo [18] who reported a decrease in the ash content from 500 to $10 \mathrm{~g} \mathrm{~kg}^{-1}$ following $\mathrm{HF}-\mathrm{HCl}$ washing. The ash contents of more than $500 \mathrm{~g} \mathrm{~kg}^{-1}$ in the insoluble fractions at $\mathrm{pH} 5$ and $\mathrm{pH} 7$ attest that there is more inorganic than organic material and is the likely reason for the lack of solubility of these fractions.

\section{Elemental composition}

The elemental composition of the humic fractions is reported in Table 1 on a moisture- and ash-free basis. Therefore, the following considerations concern the organic component of each fraction. While the insoluble fractions at $\mathrm{pH} 1$ and 3 were richer in $\mathrm{C}$ and poorer in $\mathrm{O}$ than the soluble fractions, the $\mathrm{O}$ increased at $\mathrm{pH} 5$ and 7 indicating that the precipitation $\mathrm{pH}$ of the HA affected the distribution of the functional groups between the precipitated and the liquid phase. The $\mathrm{C}$ content was lower at $\mathrm{pH} 5$ and 7 than at $\mathrm{pH} 1$ and 3 in the insoluble fractions, while the opposite was true for the soluble fractions. The $\mathrm{O}$ content and $\mathrm{O} / \mathrm{C}$ ratio were lower in the insoluble fractions at $\mathrm{pH} 1$ and 3 than at $\mathrm{pH} 5$ and 7 indicating that polarity increased along with $\mathrm{pH}$, while the opposite occurred in the soluble fractions. In the case of the $\mathrm{N}$ content, no clear trend could be identified indicating that $\mathrm{pH}$ did not affect the distribution of the $\mathrm{N}$-containing moieties in the solid or liquid phase. The $\mathrm{H}$ content was higher at $\mathrm{pH} 5$ and $\mathrm{pH} 7$ than at pH 1 and $\mathrm{pH} 3$ in both the insoluble and soluble fractions. This would appear to be an artifact, since the sum of each element present in the soluble and insoluble fractions deriving from the same alkali solution should be the same at any $\mathrm{pH}$. The highest $\mathrm{H}$ contents were found in the fractions exhibiting the highest ash contents. This suggests that the presence of inorganic components could induce an overestimation of the $\mathrm{H}$ content. One explanation for this result is that the elemental analysis includes a high-temperature incineration step (up to $1,000^{\circ} \mathrm{C}$ ) which could provoke the release of some hydration water and lead to the partial decomposition of some inorganic components, such as kaolinite, thereby releasing $\mathrm{OH}$ groups and leading to an overestimation of the hydrogen content.

\section{Acidic groups}

The carboxylic, phenolic, and total acidity distribution in each fraction are reported in Table 2. The wet method used to determine the carboxylic group content is based on titration with $\mathrm{Ca}$ acetate. The aim of this technique is to convert the complex mixture of acids in HS into an equivalent amount of acetic acid by the reaction [19]:

$$
2 \mathrm{RCOOH}+\mathrm{Ca}\left(\mathrm{CH}_{3} \mathrm{COO}\right)_{2} \leftrightarrow \mathrm{Ca}(\mathrm{RCOO})_{2}+\mathrm{CH}_{3} \mathrm{COOH}
$$

This method is reliable only if the carboxylic groups are completely combined. This is why the carboxylic group content, measured using the wet chemical method, decreased at decreasing $\mathrm{pH}$. The total acidity was not measurable at $\mathrm{pH} 5$ and 7. This was most likely due to the carbonation of the barium hydroxide solution used in titration, as reported by Stevenson [20]. Consequently, the content of phenolic groups could not be calculated.

\section{${ }^{13} \mathrm{C}$ NMR}

The distribution of the different forms of carbon calculated according to the area of the different NMR spectra regions (alkyl, 0 to $45 \mathrm{ppm}$; $\mathrm{N}$ - and O-alkyl, 45 to $95 \mathrm{ppm}$; aromatic, 95 to $160 \mathrm{ppm}$; carboxyl, 160 to $195 \mathrm{ppm}$ ) are reported in Table 2.

The amount of carboxyl carbon calculated from the integration of the signal in the 160 to $195 \mathrm{ppm}$ region was much higher than expected considering the chemical titration. This discrepancy has already been reported and discussed in the previous papers [21,22].

The insoluble fractions at $\mathrm{pH}$ values 1 and 3 are largely aromatic $(33.1 \%$ and $33.9 \%$ of the total carbon respectively) with a medium amount of aliphatic carbon (23.0\% and $21.0 \%$ of the total carbon respectively) and a low content of substituted aliphatic groups $(16.0 \%$ and $18.3 \%$ of the total carbon respectively). Similar concentrations of aromatic carbon were found in HA from histosols by ${ }^{13} \mathrm{C}$ NMR investigation $[15,23,24]$ and reflect the high maturity of the HA expected in such soils. By contrast, the soluble fractions at $\mathrm{pH} 1$ and $\mathrm{pH} 3$ contain a very low amount of aromatic $\mathrm{C}(2.9 \%$ and $7.5 \%$ of the total carbon) but are very rich in aliphatic substituted carbons (58.8\% and $42.1 \%$ of the total carbon). These results, together with the high $O$ content of these fractions (Table 1), suggest the presence of polar aliphatic compounds (sugars, amino acids, proteins, carboxylic acids) which are most likely responsible for the solubility at low $\mathrm{pH}$ values.

Similar results are obtained evaluating the degree of hydrophobicity (hydrophobic/hydrophilic carbons, HB/HI) 
Table 2 Acidic groups' concentration and distribution of $\mathrm{C}$ intensity of ${ }^{13} \mathrm{C}$ NMR spectra of humic fractions

\begin{tabular}{|c|c|c|c|c|c|c|c|c|c|}
\hline \multirow{2}{*}{\multicolumn{2}{|c|}{ Fraction }} & \multicolumn{3}{|c|}{ Acidic groups ${ }^{\mathrm{a}}\left(\mathrm{meq} \mathrm{g}^{-1}\right)$} & \multicolumn{4}{|c|}{${ }^{13} \mathrm{C}$ NMR distribution (\%) } & \multirow[t]{2}{*}{$\mathrm{HB} / \mathrm{H}$} \\
\hline & & Carboxyl & Phenol & Total acidity & 0 to $45 \mathrm{ppm}$ & 45 to $95 \mathrm{ppm}$ & 95 to $160 \mathrm{ppm}$ & 160 to $195 \mathrm{ppm}$ & \\
\hline \multirow[t]{2}{*}{ pH 1} & Insoluble & 3.8 & 7.3 & 11.1 & 23.0 & 16.0 & 33.1 & 28.0 & 1.3 \\
\hline & Soluble & 4.0 & 6.7 & 10.7 & 14.2 & 58.8 & 2.9 & 24.2 & 0.2 \\
\hline \multirow[t]{2}{*}{$\mathrm{pH} 3$} & Insoluble & 3.1 & 5.9 & 8.9 & 21.0 & 18.3 & 33.9 & 26.9 & 1.2 \\
\hline & Soluble & 2.8 & 6.7 & 9.4 & 14.5 & 42.1 & 7.5 & 35.9 & 0.3 \\
\hline \multirow[t]{2}{*}{$\mathrm{pH} 5$} & Insoluble & $n d^{b}$ & $n d^{b}$ & & $n d^{c}$ & $\mathrm{nd}^{\mathrm{c}}$ & $n d^{c}$ & $n d^{c}$ & - \\
\hline & Soluble & $n d^{b}$ & $n d^{b}$ & & 20.8 & 6.0 & 38.7 & 34.5 & 1.5 \\
\hline \multirow[t]{2}{*}{ pH 7} & Insoluble & $n d^{b}$ & $n d^{b}$ & & $n d^{c}$ & $\mathrm{nd}^{\mathrm{c}}$ & $n d^{c}$ & $n d^{c}$ & - \\
\hline & Soluble & $n d^{b}$ & $n d^{b}$ & & 19.1 & 1.3 & 35.2 & 44.3 & 1.2 \\
\hline
\end{tabular}

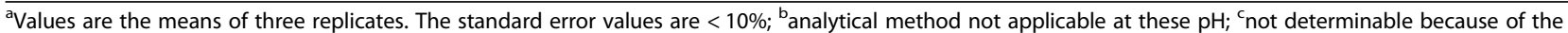
poor signal-to-noise ratio of the spectra.

as proposed by several authors [25-28]. This is given by the areas relative to resonance intervals, as follows:

$$
\frac{\mathrm{HB}}{\mathrm{HI}}=\frac{[(0-45)+(95-160)]}{[(45-95)+(160-195)]}
$$

The fractions insoluble at $\mathrm{pH} 1$ and 3 have a degree of hydrophobicity (Table 2) greater than the soluble fractions, with values $(>1.0)$ that are consistent with those observed for HA (between 0.61 and 2.87) by Piccolo et al. [26]. On the other hand, the values of the soluble fractions at $\mathrm{pH} 1$ and 3 of $\mathrm{HB} / \mathrm{HI}$ are more similar to the same authors' findings for fulvic acids $(<0.5)$.

The ${ }^{13} \mathrm{C}$ NMR spectra of the insoluble fractions at $\mathrm{pH} 5$ and 7 with a high ash content exhibit a low signal-to-noise ratio probably due to the presence of paramagnetic compounds as already observed in soils [29] and humic samples [30]. Consequently, no reliable evaluation of the carbon distribution could be made.

The soluble fractions at pH 5 and pH 7 exhibited a high content of aromatic carbon $(38.7 \%$ and $35.2 \%$ of the total carbon respectively) and a low content of $\mathrm{N}$ - and $\mathrm{O}-$ substituted aliphatic groups. This is in agreement with the decrease in soluble fraction polarity as $\mathrm{pH}$ increases, which is assumed on the basis of the elemental analysis and the degree of hydrophobicity.

The organic component of the fractions obtained at $\mathrm{pH} 5$ and 7 was also studied with ${ }^{1} \mathrm{H}$ NMR in order to obtain more information regarding their chemical characteristics. This technique proved easier to use with samples having a higher ash content than did ${ }^{13} \mathrm{C}$ NMR. The ${ }^{1} \mathrm{H}$ NMR data agree well with the data obtained from the ${ }^{13} \mathrm{C}$ NMR but tend to underestimate the aromaticity, above all when the aromatic molecules are substituted with atoms other than hydrogen [31].

The distribution of the different forms of hydrogen was calculated by integration in three regions of the spectrum ( 0.5 to $3 \mathrm{ppm}, 3$ to $4.2 \mathrm{ppm}$, and 6 to $8 \mathrm{ppm}$ ) and expressed as a percentage of the total area of each spectrum. The allocation of the three regions was based on the work of Francioso et al. [32]. The region from 0.5 to $3 \mathrm{ppm}$ corresponds to the $\mathrm{H}$ forms linked to aliphatic groups, the region from 3 to $4.2 \mathrm{ppm}$ is assigned to the $\mathrm{H}$ forms linked to carbohydrate structures, and finally the region between 6 and $8 \mathrm{ppm}$ is allocated to the $\mathrm{H}$ forms linked to aromatic molecules.

From Table 3, which relates to the distribution of the ${ }^{1} \mathrm{H}$ forms, it can be seen that the aliphatic region is similar for all the fractions obtained at $\mathrm{pH} 5$ and 7 , while the region related to carbohydrates (between 3 and $4.2 \mathrm{ppm}$ ) is higher in insoluble fractions than soluble. Moreover, the latter is more aromatic than the insoluble one. In agreement with the elemental analysis, these components are more polar than the soluble fractions (Table 1).

\section{FT-IR}

The FT-IR spectra indicate some large differences between the humic fractions, attesting to the different structures of both the inorganic and organic material (Figure 2). The spectra of the insoluble fractions at $\mathrm{pH} 5$ and 7 (containing more than 50\% inorganic component) were identical and dominated by the intense absorption of the $\mathrm{Si}-\mathrm{O}$ vibration centered at $1,030 \mathrm{~cm}^{-1}$ typical of montmorillonite [33]. The other bands attributable to the inorganic components have the same frequencies as those of montmorillonite defiled with kaolinite [33,34] as follows: $3,696 \mathrm{~cm}^{-1}$, OH stretching of inner-surface hydroxyl groups of kaolinite; 3,621 $\mathrm{cm}^{-1}, \mathrm{OH}$ stretching

Table 3 Distribution of $\mathrm{H}$ intensity of the ${ }^{1} \mathrm{H}$ NMR spectra of the humic fractions

\begin{tabular}{lllll}
\hline Fraction & \multicolumn{3}{c}{${ }^{\mathbf{1}} \mathbf{H}$ NMR distribution (\%) } \\
\cline { 3 - 5 } & & $\mathbf{0 . 5}$ to $\mathbf{3 . 0} \mathbf{~ p p m}$ & $\mathbf{3 . 0}$ to $\mathbf{4 . 2} \mathbf{~ p p m}$ & $\mathbf{6 . 0}$ to $\mathbf{8 . 0} \mathbf{~ p p m}$ \\
\hline $\mathrm{pH} \mathrm{5}$ & Insoluble & 45.6 & 36.7 & 17.7 \\
& Soluble & 45.2 & 23.2 & 31.6 \\
$\mathrm{pH} \mathrm{7}$ & Insoluble & 47.6 & 40.3 & 12.1 \\
& Soluble & 46.9 & 20.5 & 32.6 \\
\hline
\end{tabular}




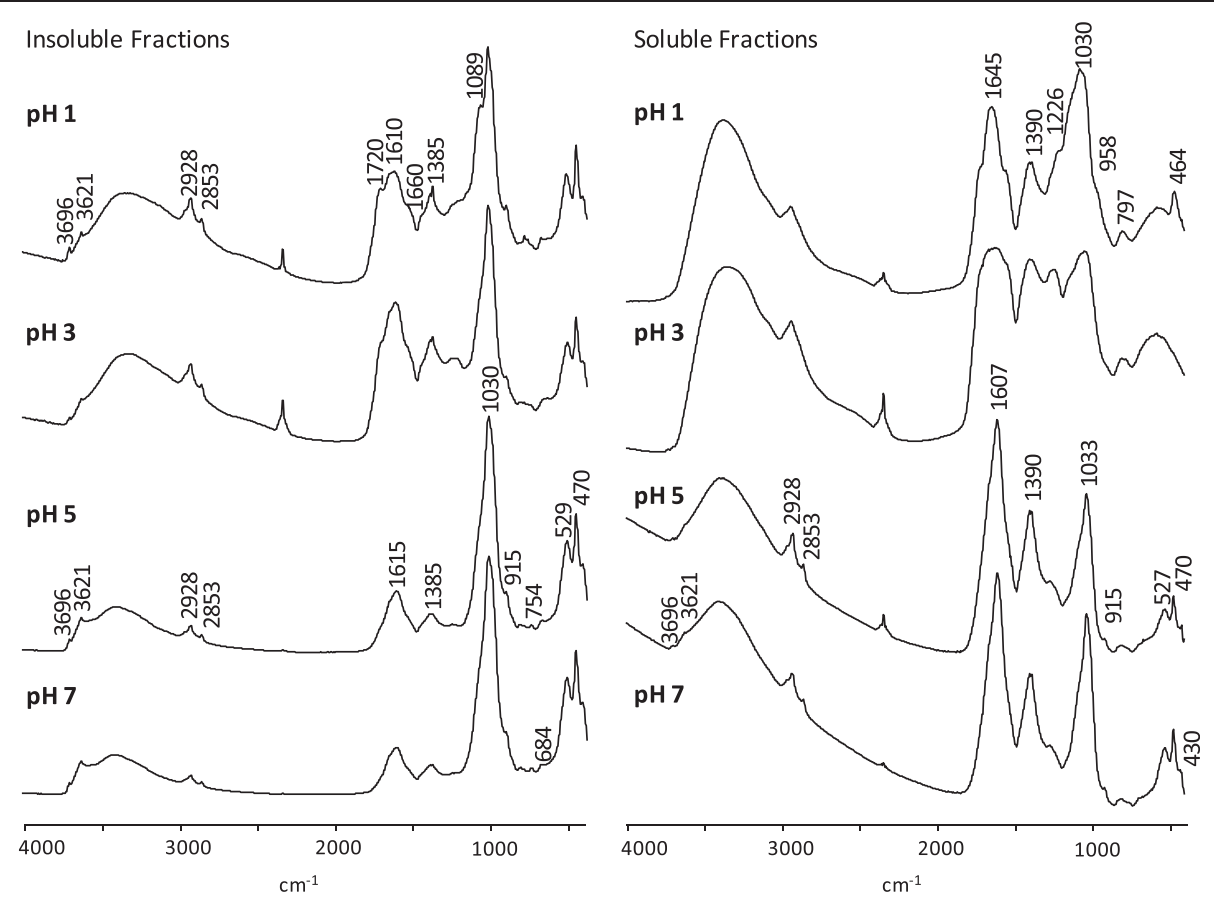

Figure 2 FT-IR spectra of insoluble and soluble humic acid fractions at different $\mathrm{pH}$ values.

of hydroxyl groups; $915 \mathrm{~cm}^{-1}$, AlAlOH deformation; $754 \mathrm{~cm}^{-1}$, Si-O perpendicular (kaolinite); $470 \mathrm{~cm}^{-1}$, Si-OSi deformation; $430 \mathrm{~cm}^{-1}$, Si-O deformation (kaolinite). The band at $529 \mathrm{~cm}^{-1}$ could be the Al-O-Si deformation of montmorillonite, although it is generally reported at lower frequencies $\left(521\right.$ to $523 \mathrm{~cm}^{-1}$ ). Some of the typical bands of montmorillonite are missing (790, 623, and $578 \mathrm{~cm}^{-1}$ ). The lack of such bands has already been observed in soil montmorillonites and attributed to a larger disorder which provokes the broadening and vanishing of these bands [33]. Besides the bands of the inorganic compounds, the main organic bands are the aliphatic absorptions at 2,928 and $2,853 \mathrm{~cm}^{-1}\left(\mathrm{CH}_{2}\right.$ stretching). Also, the two bands centered at 1,615 and $1,385 \mathrm{~cm}^{-1}$, typical of the asymmetric and symmetric vibrations of carboxylates, reflect the presence of metal carboxylates.

The spectra of the soluble fractions at $\mathrm{pH} 5$ and $\mathrm{pH} 7$ show the same bands as those attributed to the vibrations of kaolinite and montmorillonite for the insoluble fractions $\left(3,696,3,620,1,033,915,527,470\right.$, and $\left.430 \mathrm{~cm}^{-1}\right)$ but with lower intensity due to their lower ash content. The $\mathrm{COOH}$ vibration is missing, while very strong bands are present at 1,607 $\left(v_{\mathrm{as}} \mathrm{COO}^{-}\right)$and $1,390 \mathrm{~cm}^{-1}\left(v_{\mathrm{s}} \mathrm{COO}^{-}\right)$. The frequency of the $v_{\text {as }} \mathrm{COO}^{-}$has been seen to decrease in parallel to an increase in the ionic radii of the metallic ion [35]. According to these authors, the $v_{\mathrm{as}} \mathrm{COO}^{-}$band shift toward higher frequencies corresponds to the transition from ionic to covalent bond and can be used to establish the ionic-covalent nature of metal carboxylates. This statement was contested by Piccolo and Stevenson [36], given the possibility that the metal-complexed ketonic group could give a band in the 1,620 to $1,610 \mathrm{~cm}^{-1}$ region. However, the $v_{\mathrm{as}} \mathrm{COO}^{-}$on the spectra of the soluble fractions at $\mathrm{pH} 5$ and $7\left(1,607 \mathrm{~cm}^{-1}\right)$ does not fall in the ketonic region and is between those reported by Vinkler et al. [35] for Na humate $\left(1,590 \mathrm{~cm}^{-1}\right)$ and by Piccolo and Stevenson [36] for $\mathrm{K}$ humate at pH $5\left(1,610 \mathrm{~cm}^{-1}\right)$. This suggests the formation of ionic humates, probably with a great presence of $\mathrm{Na}$ ions in the solution at these $\mathrm{pH}$ values.

The spectra of the insoluble fraction at $\mathrm{pH} 1$ and $\mathrm{pH} 3$ exhibit the same, but weaker, bands as those attributed to the inorganic component in the insoluble fractions at $\mathrm{pH} 5$ and 7. In contrast, the HA bands are stronger and some new peaks are present, in particular, the $\mathrm{COOH}$ vibration at $1,720 \mathrm{~cm}^{-1}$; the band in the 1,610 to $1,660 \mathrm{~cm}^{-1}$ region is broader with a shoulder at $1,660 \mathrm{~cm}^{-1}$ and is likely due to an overlap between $v_{\text {as }} \mathrm{COO}^{-}$vibration, aromatic $-\mathrm{C}=\mathrm{C}$ vibration and $\mathrm{N}$-containing groups. A partial influence on this band can also come from the $\mathrm{OH}$ stretching of water bonded to the clay minerals which has been seen to absorb in the 1,630 to $1,660 \mathrm{~cm}^{-1}$ range [33].

The spectrum of the insoluble fraction at $\mathrm{pH} 1$ exhibits a strong band at $1,089 \mathrm{~cm}^{-1}$ similar to that shown on the spectrum of a montmorillonite and attributed to the $\mathrm{Si}-\mathrm{O}$ stretching of a cristobalite-like phase impurity [34].

The spectra of the soluble fractions at $\mathrm{pH} 1$ and 3, having the lowest ash content, exhibit the typical features of the HS spectra eliminating part of the diagnostic 
bands of the inorganic components. The silicates O-Si-O vibration band centered at $1,030 \mathrm{~cm}^{-1}$ on the other spectra is broad and shifted at higher frequencies (up to $1,075 \mathrm{~cm}^{-1}$ at $\mathrm{pH} 1$ ). A Si-O vibration at $1,075 \mathrm{~cm}^{-1}$, besides weaker bands at $1,200,958,797$, and $464 \mathrm{~cm}^{-1}$, has been attributed to the silica gel [37]. The same bands are present on the spectrum of the soluble fraction at $\mathrm{pH} 1$ which also exhibits the two carboxylate group bands $\left(1,645\right.$ and $\left.1,390 \mathrm{~cm}^{-1}\right)$. Very similar spectra were reported for the soluble products formed between hydroxy-Al ions and orthosilicic acid in the presence of citric acid [37] and HS [38]. This suggests that the fractions which do not precipitate at low $\mathrm{pH}$ are organo-mineral colloids in which the inorganic phase is similar to the silica gel. However, the frequency of the broad band centered at $1,645 \mathrm{~cm}^{-1}$ is higher than those reported by Vinkler et al. [35] also in the case of covalent humates with $\mathrm{Fe}$ and $\mathrm{Al}\left(1,625 \mathrm{~cm}^{-1}\right)$ and should be overlapped by other absorptions, for example, the $\mathrm{OH}$ vibration of water molecules bonded to silica gel which occurs at $1,630 \mathrm{~cm}^{-1}$ [33].

Although the FT-IR spectra of these fractions provided evidence of the presence of phyllosilicates and silica gel, we cannot exclude that the inorganic fractions also contain iron and aluminum oxides. The $\mathrm{FeOH}$ bending and the $\mathrm{Fe}-\mathrm{O}$ stretching of a $\mathrm{Fe}(\mathrm{III})$ synthetic polycation absorb at 550 and $680 \mathrm{~cm}^{-1}$ respectively $[39,40]$. Other authors report that the main absorption of ferrihydrite took place at $587 \mathrm{~cm}^{-1}$ while hematite gave sharp bands at 460 and $580 \mathrm{~cm}^{-1}$ [41]. On the spectra for those insoluble fractions at $\mathrm{pH} 5$ and $\mathrm{pH}$ 7, a weak band is present at $684 \mathrm{~cm}^{-1}$ which could be attributed to $\mathrm{Fe}-\mathrm{O}$ stretching, while the other bands typical of Fe vibrations could be overlapped or dwarfed by the strong absorption of silicates. The hydroxides are generally identified by several diagnostic bands in the $\mathrm{OH}$ stretching region, their number and frequency depending on the grade of crystallinity of the minerals [42]. However, in the presence of silicates with water in the interlayer, these bands have been seen to mix in a single broad absorption band in the 3,000 to $3,630 \mathrm{~cm}^{-1}$ range [42]. Therefore, the lack of such bands in our samples does not mean that they do not contain aluminum hydroxides. The other typical $\mathrm{Al}$ hydroxide bands are at 1,025, 970, and $531 \mathrm{~cm}^{-1}$ [43] The first two bands are overlapped by $\mathrm{Si}-\mathrm{O}$ absorption at $1,030 \mathrm{~cm}^{-1}$, but a strong band at $530 \mathrm{~cm}^{-1}$ cannot be attributed to silicates and could indicate the presence of aluminum hydroxides.

\section{Metal concentrations in the inorganic components}

The total metal content and the DCB extractable concentration of $\mathrm{Al}$ and $\mathrm{Fe}$ in the humic fractions are reported in Tables 4 and 5. The highest concentrations of $\mathrm{Si}$ and $\mathrm{Al}$ (as total $\mathrm{Al}$ ) were found in the insoluble fractions, which indicate the presence of phyllosilicates (Table 4). In the insoluble fractions at $\mathrm{pH} 5$ and $\mathrm{pH} 7$, less than $5 \% \mathrm{Al}$ was DCB extractable showing that this metal was mainly present in clay mineral structures. In the insoluble fractions at $\mathrm{pH} 1$ and $\mathrm{pH} 3,28 \%$ and $32 \%$ of the total aluminum were DCB extractable indicating that part of the $\mathrm{Al}$ was present as oxyhydroxides or $\mathrm{HA}$ bound. In contrast, the DCB extractable Fe was more abundant in the insoluble fractions at $\mathrm{pH} 1$ and $3(64 \%)$ than at $\mathrm{pH} 5$ and 7 (34 and 46\% respectively). The high proportion of DCB extractable Fe in the HA-rich fractions at $\mathrm{pH} 1$ and 3 suggests the presence of organo-metallic compounds in which the $\mathrm{Fe}$ atom could act as a bridge between the humic and inorganic phases.

In the soluble fraction at $\mathrm{pH} 3$, all the $\mathrm{Al}$ and $\mathrm{Fe}$ were DCB extractable attesting to a lack of clay minerals, which agrees with the silica-gel structure deduced from the FT-IR spectra. In the soluble fractions at $\mathrm{pH} 5$ and 7 , more than $70 \%$ of the total amount of Fe and more than $40 \%$ of the total amount of $\mathrm{Al}$ were $\mathrm{DCB}$ extractable indicating the presence of oxyhydroxides and HA bound forms.

The presence of $\mathrm{Na}$ humates and phyllosilicates in the soluble and insoluble fractions, respectively, affected the $\mathrm{Na}$ concentration with the increasing of $\mathrm{pH}$ value (Table 5).

$\mathrm{K}$ was much less abundant than Na. The highest concentrations were found in the insoluble fractions suggesting that besides $\mathrm{Na}^{+}, \mathrm{K}^{+}$also neutralized the negative surface charges of the clay minerals. $\mathrm{Mg}$ followed more or less the same trend as $\mathrm{K}$. As far as Ca was concerned, no trend could be identified suggesting that this cation is exchangeable on both the phyllosilicate and Ca humates. It can also act as a bridge between the organic and inorganic phases.

\section{Discussion}

The HA fraction insoluble at $\mathrm{pH} 1$ might correspond to the HA extracted following the IHSS procedure, except for the purification step. It has the typical composition of a mature HA formed in organic soils in a temperate climate: a high acidic group content and high aromaticity, but a low content of $\mathrm{O}$ - and $\mathrm{N}$-containing groups [44]. A compound with nearly the same characteristics is obtained at $\mathrm{pH} 3$. The inorganic phase in the fraction insoluble at $\mathrm{pH} 1$ and $\mathrm{pH} 3$ accounts for about $25 \%$ of the total. It is largely constituted by clay minerals (montmorillonite-kaolinite) which only in drastic treatments, including $\mathrm{HF}-\mathrm{HCl}$, are able to dissolve. We cannot establish whether these organo-mineral complexes were present in the soil and have been extracted or whether they are formed between two dissolved separated phases. On the other hand, the binding of HA to kaolinite and montmorillonite at $\mathrm{pH} \leq 3$ has been assessed by several adsorption studies [45-49]. The interaction between humic substances and clay minerals can include specific 
Table 4 Total and DCB extractable Al and Fe in the humic fractions

\begin{tabular}{|c|c|c|c|c|c|c|c|c|}
\hline \multirow[t]{3}{*}{ Fraction } & & \multirow{3}{*}{$\begin{array}{l}\text { Si } \\
\text { Total } \\
\left(\mathrm{mol} \mathrm{kg}^{-1}\right)\end{array}$} & \multicolumn{3}{|c|}{$\mathrm{Fe}$} & \multicolumn{3}{|c|}{ Al } \\
\hline & & & \multirow{2}{*}{$\begin{array}{l}\text { Total } \\
\left(\mathrm{mol} \mathrm{kg}{ }^{-1}\right)\end{array}$} & \multicolumn{2}{|c|}{ DCB extractable } & \multirow{2}{*}{$\begin{array}{l}\text { Total } \\
\left(\mathrm{mol} \mathrm{kg}^{-1}\right)\end{array}$} & \multicolumn{2}{|c|}{ DCB extractable } \\
\hline & & & & $\left(\mathrm{mol} \mathrm{kg}^{-1}\right)$ & $(\%)^{a}$ & & $\left(\mathrm{~mol} \mathrm{~kg}^{-1}\right)$ & $(\%)^{a}$ \\
\hline \multirow[t]{2}{*}{ pH 1} & Insoluble & $1.81^{\mathrm{a}}$ & $0.47^{\text {abe }}$ & $0.30^{\mathrm{ab}}$ & 64 & $1.02^{\mathrm{a}}$ & $0.29^{\mathrm{ac}}$ & 28 \\
\hline & Soluble & nd & nd & nd & nd & nd & nd & nd \\
\hline \multirow[t]{2}{*}{$\mathrm{pH} 3$} & Insoluble & $1.67^{\text {ae }}$ & $0.60^{\text {ace }}$ & $0.35^{\mathrm{ab}}$ & 58 & $1.03^{\mathrm{a}}$ & $0.33^{\mathrm{a}}$ & 32 \\
\hline & Soluble & $0.87^{\text {be }}$ & $0.24^{\text {bde }}$ & $0.24^{\mathrm{a}}$ & 100 & $0.08^{b}$ & $0.10^{\mathrm{b}}$ & 125 \\
\hline \multirow[t]{2}{*}{$\mathrm{pH} 5$} & Insoluble & $3.67^{c}$ & $0.73^{c}$ & $0.25^{\mathrm{a}}$ & 34 & $2.33^{\mathrm{cd}}$ & $0.09^{b}$ & 4 \\
\hline & Soluble & $0.84^{\text {be }}$ & $0.37^{\text {de }}$ & $0.28^{\mathrm{ab}}$ & 76 & $0.46^{\mathrm{a}}$ & $0.22^{c}$ & 48 \\
\hline \multirow[t]{2}{*}{ pH 7} & Insoluble & $4.22^{d}$ & $0.83^{c}$ & $0.37^{b}$ & 46 & $2.74^{d}$ & $0.10^{\mathrm{b}}$ & 4 \\
\hline & Soluble & $1.26^{\mathrm{e}}$ & $0.38^{e}$ & $0.27^{\mathrm{ab}}$ & 71 & $0.60^{\mathrm{a}}$ & $0.26^{c}$ & 43 \\
\hline
\end{tabular}

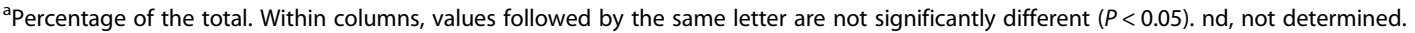

and columbic interactions, but Schutless et al. [46] recommend being careful in interpreting adsorption studies since at low $\mathrm{pH}$ values, adsorption and precipitation mechanisms are difficult to differentiate. The organomineral aggregates could also have been stabilized by the presence of $\mathrm{Al}$ and $\mathrm{Fe}$, not included in phyllosilicate structures, and low amounts of alkaline and alkaline earth metals. Polyvalent cations are known to promote the interaction of HA with phyllosilicates through the formation of cation bridges [47,50].

The soluble fractions at $\mathrm{pH} 1$ and $\mathrm{pH} 3$ account for less than $10 \%$ of the total material but this data is underestimated because part of this fraction has been lost during the dialysis step. The organic phase contains less than $10 \%$ aromatic carbon and is rich in $\mathrm{O}$ - and $\mathrm{N}$-containing groups and carboxylic groups. Therefore, it should be composed of soluble polar molecules such as polysaccharides, organic acids, and amino acids. The inorganic fraction is mainly composed of a silica gel-like phase whose formation could be an artifact due to the polymerization of silicic acid by freeze-drying [34]. On the other hand, orthosilicic acid occurs in solutions and on the surface of

Table 5 Total metal concentration of the humic acid fractions

\begin{tabular}{|c|c|c|c|c|c|}
\hline \multicolumn{2}{|c|}{ Fraction } & \multirow{2}{*}{$\begin{array}{l}\mathrm{Ca} \\
\left(\mathrm{mol} \mathrm{kg}^{-1}\right) \\
0.07^{\text {ad }}\end{array}$} & \multirow{2}{*}{$\begin{array}{l}\mathbf{K} \\
\left(\mathbf{m o l ~ k g}^{-1}\right) \\
0.13^{\text {ad }}\end{array}$} & \multirow{2}{*}{$\begin{array}{l}\mathrm{Mg} \\
\left(\mathrm{mol} \mathrm{kg}^{-1}\right)\end{array}$} & \multirow{2}{*}{$\begin{array}{l}\mathrm{Na} \\
\left(\mathrm{mol} \mathrm{kg}^{-1}\right) \\
0.31^{\mathrm{a}}\end{array}$} \\
\hline pH 1 & Insoluble & & & & \\
\hline & Soluble & nd & nd & nd & nd \\
\hline \multirow[t]{2}{*}{$\mathrm{pH} 3$} & Insoluble & $0.11^{\mathrm{abcd}}$ & $0.18^{\mathrm{a}}$ & $0.22^{\mathrm{a}}$ & $0.50^{\mathrm{a}}$ \\
\hline & Soluble & $0.14^{\mathrm{abcd}}$ & $0.06^{\mathrm{b}}$ & $0.03^{b}$ & $1.69^{\mathrm{b}}$ \\
\hline \multirow[t]{2}{*}{ pH 5} & Insoluble & $0.12^{\mathrm{abcd}}$ & $0.28 \mathrm{c}$ & $0.55 c$ & $0.97^{c}$ \\
\hline & Soluble & $0.16^{\mathrm{bcd}}$ & $0.07^{\mathrm{b}}$ & $0.11^{d}$ & $2.32^{d}$ \\
\hline \multirow[t]{2}{*}{$\mathrm{pH} 7$} & Insoluble & $0.09^{c d}$ & $0.33^{c}$ & $0.67^{e}$ & $1.00^{c}$ \\
\hline & Soluble & $0.14^{d}$ & $0.10^{b d}$ & $0.17^{\mathrm{ad}}$ & $2.21^{d}$ \\
\hline
\end{tabular}

Within columns, values followed by the same letter are not significantly different $(P<0.05)$. nd, not determined because of the low amount of sample. solid particles in soil [51]. The FT-IR spectra suggest the presence of $\mathrm{Al}$ and $\mathrm{Fe}$ oxides whose solubility is consistent with the low $\mathrm{pH}$ and a possible complexation by small organic molecules.

The fractions insoluble at $\mathrm{pH} 5$ and $\mathrm{pH} 7$ contain a large amount of inorganic material (54\% and $61 \%$ at $\mathrm{pH} 5$ and 7 respectively). The inorganic phase mainly consists in phyllosilicates (kaolinite and montmorillonite).

Less than $5 \% \mathrm{Al}$ is DCB extractable indicating that all the $\mathrm{Al}$ atoms are included in phyllosilicate structures.

These results suggest that the material precipitated at pH 5 and 7 does not exhibit a typical humic structure. It is more likely an organo-mineral association of clay minerals bound to polar molecules. This result is in agreement with the study by Yong and Mourato [52], performed on the interaction of kaolinite and dextran, which demonstrated the capability of polysaccharides to act as flocculants of clay minerals.

The soluble fractions at $\mathrm{pH} 5$ and $\mathrm{pH} 7$ account for $73 \%$ and $90 \%$ of the total humic material, respectively. These fractions are particularly rich in aromatic and aliphatic groups and exhibit a very low polar group content as indicated by both the NMR results and the low O/C ratio. The fact that most of the polar molecules were no longer present in this typical humic material, but precipitated as organo-mineral associations (see the above paragraph), suggests that contrary to the usual assumption, they were not strongly bound to the humic acid.

There is evidence of the presence of kaolinite and montmorillonite whose solubility, probably as a colloidal solution, is promoted by the presence of large amounts of $\mathrm{Na}^{+}$. On the other hand, the phyllosilicates account for only part of the inorganic phase since more than $40 \% \mathrm{Al}$ and $70 \% \mathrm{Fe}$ are $\mathrm{DCB}$ extractable, indicating the presence of oxihydroxides and/or $\mathrm{Al}$ and $\mathrm{Fe}$ humates. The increased solubility of the humic fraction at increasing $\mathrm{pH}$ is expected due to the deprotonation of the carboxylic and phenolic groups. The carboxyl groups are 
known to be completely undissociated at $\mathrm{pH}<3$ and mostly ionized at $\mathrm{pH}>7$, while the dissociation of the hydroxyl phenolic groups occurs at higher $\mathrm{pH}$ values. It is surprising that this fraction, whose organic phase has the typical features of mature humic acid, rich in aromatic and aliphatic moieties and therefore largely hydrophobic, was soluble at $\mathrm{pH} 5$.

Our results are in contrast with the reported data concerning the solubility of HA which are usually found to be completely soluble at much higher $\mathrm{pH}$ (at least $>8$ ) [53]. One of the reasons for such a discrepancy could be the solubilization procedure which several studies report as affecting the behavior of the humic substances. Klucakova et al. [54] have observed that the fresh, wet HA precipitate is very easily peptized upon washing with water which is accompanied by a gradual increase in $\mathrm{pH}$. Solubility of dried, solid preparation in water is much more difficult, especially when not freeze-dried. This last observation is consistent with the experiments by Brigante et al. [12] which observed a complete solubilization only at $\mathrm{pH} \geq 9$ (eliminato un pezzo perché usato nell'introduzione). The discrepancy between our results and those of Brigante et al. [12] could be explained by the different procedure for modifying the $\mathrm{pH}$. In our experiment, we started from a humate solution to which amounts of $\mathrm{HCl}$ were added, while Brigante et al. [12] started from a solid humic acid brought to higher $\mathrm{pH}$ by $\mathrm{NaOH}$ addition. This suggests that it is less easy to form aggregates by acidifying a humate solution than to disrupt them by bringing solid HA to higher $\mathrm{pH}$. Therefore, the solubilization-precipitation process of HS should behave hysteretically.

Our study points out that a decrease in the $\mathrm{pH}$ of a humate solution from 5 to 3 provokes a drastic change in the aggregation of the humic molecules. This $\mathrm{pH}$ range has not yet been fully investigated. The average $\mathrm{p} K_{\mathrm{a}}$ of the carboxylic groups of the HA is $4.5[55,56]$. More recent studies [57], based on the Anderson-Hasselbach interpretation, have established that the apparent $\mathrm{p} K_{\mathrm{a}}$ of a peat humic acid was 4.93. Alvarez-Puebla and Garrido [58] measured the zeta potential of a grey humic acid against $\mathrm{pH}$ and observed a drop in the $\mathrm{pH}$ intervals 3.6 to 4.2 and 5.9 to 6.2 , with a section of null slope between the two. The null slope section between these drops seems to indicate that the electrokinetic properties of the colloids do not change in this interval. The plot of the size variation against $\mathrm{pH}$ showed great similarity. The porosity measured through $\mathrm{CO}_{2}$ adsorption isotherms indicated a decrease in the pore size and surface area between $\mathrm{pH} 4$ and $\mathrm{pH} 5$, while no relevant difference was observed between $\mathrm{pH} 2$ and $\mathrm{pH}$ 4. The results of Alvarez-Puebla and Garrido [58] indicate that the decrease in colloidal size appears to be more influenced by the ionization of phenolic groups than by the ionization of carboxylic groups. This is because the phenolic groups and the undissociated carboxylic groups can participate in forming hydrogen bonds thus promoting the coiling of the molecules and the formation of aggregates.

Another factor affecting the solubility of HS is the amount and composition of the inorganic phase. Extracted $\mathrm{HA}$ are usually treated with $\mathrm{HCl}-\mathrm{HF}$ solution until a low ash content is reached, usually $<2 \%$. Little attention is given to the residual inorganic phase because it is assumed that it does not affect the behavior of the organic material. Klucakova et al. [59] reported the equilibrium constants concerning lignitic HA treated or not treated with $\mathrm{HCl}-\mathrm{HF}$. From these results, it appears that the ratio between $\mathrm{HA}(\mathrm{aq})$ and $\mathrm{HA}(\mathrm{s})$ decreased as ash content increased.

To better understand the behavior of the $\mathrm{HA}$ at $\mathrm{pH} 5$, especially the possibility of forming metallic humates, it would be useful to have more information on the nature of the carboxylic groups. Powell and Fenton [53] performed a titration of the carboxylic groups of a peat HA. They found that up to $20 \%$ of the $\mathrm{COOH}$ groups were weak acids, with titration constants above $\log K=5.0$, indicative of polyprotic moieties which contribute significantly to the metal binding properties of HS. This suggests that the dissociated $\mathrm{COOH}$ groups below $\mathrm{pH} 5$ are monoprotic moieties unable to bind bivalent and trivalent cations. The soluble fractions at $\mathrm{pH} 5$ and 7 contain more than $20 \%$ of inorganic material probably present as a colloidal solution whose stability is promoted by the sodium ions. According to the results of Powell and Fenton [53], the formation of metal humates with bivalent and trivalent ions could take place at $\mathrm{pH}$ 7. On the other hand, the complete ionization of the carboxylic groups at this $\mathrm{pH}$ could explain the solubility of the corresponding fraction.

\section{Conclusions}

Our results indicate a notable change in the behavior and composition of the humic acid we studied in the $\mathrm{pH}$ range from 3 to 5 . In this $\mathrm{pH}$ range, the humic acid changes from insoluble to a colloidal solution, notwithstanding the hydrogen bonds and weak molecular forces. On the other hand, it has also been demonstrated $[54,59]$ that solubilization of HA is not only dependent on the deprotonation of $\mathrm{COOH}$ and that undissociated molecules can be water soluble.

Most of the fraction consisting in O-containing groups, notwithstanding its high polarity, does not remain in solution at $\mathrm{pH} 5$ and $\mathrm{pH} 7$ but precipitates with the phyllosilicate-rich inorganic phase. This suggests that it is not strongly bound to the humic fraction.

At $\mathrm{pH} 1$ and $\mathrm{pH} 3$, the inorganic phase bound to the insoluble humic material was largely constituted by clay minerals and some $\mathrm{Al}$ and $\mathrm{Fe}$ hydroxides. Moreover, at lower $\mathrm{pH}$ values, the soluble fractions isolated were 
very poor and composed of a silica gel-like associated with polar organic material.

The results emphasize the effect that the preparation procedure can have on the behavior of the humic substances.

\section{Abbreviations}

HS: humic substances; HA: humic acids; IHSS: International Humic Substances Society; NMR: nuclear magnetic resonance.

\section{Competing interests}

The authors declare that they have no competing interests.

\section{Authors' contributions}

The work presented here was carried out in collaboration between all authors. $M N$ defined the research theme; $M N$ and $A B$ designed methods and experiments; DV carried out the laboratory experiments, $A B, M G$ and $M N$ analyzed the data, interpreted the results, $A B$ and $M N$ wrote the paper. All authors have contributed to, seen, and approved the final manuscript.

\section{Author details}

${ }^{1}$ Dipartimento di Scienze delle Produzioni Agrarie e Alimentari, University of Catania, Via S. Sofia 98, 95123 Catania (CT), Italy. ${ }^{2}$ Dipartimento di Scienze Agrarie, Forestali e Alimentari, University of Turin, Largo Paolo Braccini 2, 10095 Grugliasco (TO), Italy.

\section{Received: 25 February 2014 Accepted: 14 July 2014}

\section{Published online: 05 August 2014}

\section{References}

1. Lal R (2004) Soil carbon sequestration impacts on global climate change and food security. Science 30:1623-1627

2. Piccolo A, Spaccini R, Nieder R, Richter J (2004) Sequestration of a biologically labile organic carbon in soils by humified organic matter. Clim Change 67:329-343

3. Nardi S, Muscolo A, Vaccaro S, Baiano S, Spaccini R, Piccolo A (2007) Relationship between molecular characteristics of soil humic fractions and glycolytic pathway and Krebs cycle in maize seedlings. Soil Biol Biochem 39:3138-3146

4. Canellas LP, Zandonadi DB, Busato JG, Baldotto MA, Simoes ML, Martin-Neto L, Facanha AR, Spaccini R, Piccolo A (2008) Bioactivity and chemical characteristics of humic acids from tropical soils sequence. Soil Sci 173:624-637

5. Nebbioso A, Piccolo A (2009) Molecular rigidity and diffusivity of $\mathrm{Al}^{3+}$ and $\mathrm{Ca}^{2+}$ humates as revealed by NMR spectroscopy. Environ Sci Technol 43:2417-2424

6. Nègre M, Boursier C, Abbate C, Baglieri A, Gennari M (2008) Use of soil colloids to evaluate adsorption of phenanthrene and its mobilization by different solutions. J Environ Sci Health A 43:443-451

7. Baglieri A, Abbate C, Borzi D, Gennari M (2009) Adsorption of pyrimethanil on soil and some of its colloids. Fresenius Environ Bull 18:578-584

8. Hayes MHB, Swift RS, Wardle RE, Brown JK (1975) Humic materials from an organic soil: a comparison of extractant and of properties of extracts. Geoderma 13:231-245

9. Swift RS (1996) Organic matter characterisation. In: Methods of soil analysis Part 3. Chemical methods. Soil Science Society of America and American Society of Agronomy, Madison, pp 1011-1069

10. Piccolo A, Conte P (2000) Molecular size of humic substances. Supramolecular associations versus macromolecular polymers. Adv Environ Res 3:508-521

11. Sutton B, Sposito G (2005) Molecular structure in soil humic substances. Environ Sci Technol 39:9009-9015

12. Brigante M, Zanini G, Avena M (2007) On the dissolution kinetics of humic acid particles: effects of $\mathrm{pH}$, temperature and $\mathrm{Ca}^{2+}$ concentration. Colloids Surf A: Physicochem Eng Aspects 294:64-70

13. Choudhri MB, Stevenson FJ (1957) Chemical and physicochemical properties of soil humic colloids: III. Extraction of organic matter from soil. Soil Sci Soc Am Proc 21:508-513

14. Gascho GJ, Stevenson FJ (1968) Improved method for extracting organic matter from soil. Soil Sci Soc Am Proc 32:117-119
15. Nègre M, Vindrola $D$, Spera $S$, Ferraris L, Gennari M (2002) Effect of the chemical composition of soil humic acids on their viscosity, surface pressure and morphology. Soil Sci 167:636-651

16. Sanders JKM, Hunter BK (1993) Modern NMR spectroscopy: a guide for chemists, 2nd edn. Oxford University Press, New York

17. Mehra OP, Jackson ML (1960) Iron oxide removal from soils and clays by a dithionite-citrate system buffered with sodium bicarbonate. Clays and Clay Minerals 7:317-327, Proceedings of the 7th National Conference on Clays and Clay Minerals, Washington, DC

18. Piccolo A (1988) Characteristics of soil humic extracts obtained by some organic and inorganic solvents and purified by HCl-HF treatment. Soil Sci 146:418-426

19. Perdue EM (1985) Acidic functional groups of humic substances. In: Aiken GR, McKnight DM, Wershaw RL, McCarthy P (eds) Humic substances in soil, sediment, and water: geochemistry, isolation and characterization. Wiley, New York, pp 493-526

20. Stevenson FJ (1994) Extraction, fractionation, and general chemica composition of soil organic matter. In: Stevenson FJ (ed) Humus chemistry. Genesis, composition, reactions. Wiley, New York, pp 26-54

21. Hatcher PG, Schnitzer M, Dennis LW, Maciel GE (1981) Aromaticity of humic substances in soils. Soil Sci Soc Am J 45:1089-1094

22. Schnitzer M, Preston CM (1986) Analysis of humic acids by solution and solidstate carbon-13 nuclear magnetic resonance. Soil Sci Soc Am J 50:326-331

23. Mao JD, Hu WG, Schmidt-Rohr K, Davies G, Ghabbour EA, Xing B (2000) Quantitative characterization of humic substances by solid-state carbon-13 nuclear magnetic resonance. Soil Sci Soc Am J 64:873-884

24. Yanagi Y, Tamaki H, Otsuka H, Fujitake N (2002) Comparison of decolorization by microrganisms of HA with different C-13 NMR properties. Soil Biol Biochem 34:729-733

25. Spaccini R, Mbagwu JSC, Conte P, Piccolo A (2006) Changes of humic substances characteristics from forested to cultivated soils in Ethiopia. Geoderma 132:9-19

26. Piccolo A, Conte P, Spaccini R, Mbagwu JSC (2005) Influence of land use on the characteristics of humic substances in some tropical soils of Nigeria. Eur J Soil Sci 56:343-352

27. Saab SD, Martin-Neto L (2007) Condensed aromatic rings and E4/E6 ratio: humic acids in gleysoils studied by NMR CP/MAS C-13 and dipolar dephasing. Quim Nova 30:260-263

28. Forte C, Piazzi A, Pizzanelli S, Certini G (2006) CP MAS ${ }^{13} \mathrm{C}$ spectral editing and relative quantitation of a soil sample. Solid State Nucl Mag 30:81-88

29. Mathers NJ, Xu Z, Berners-Price J, Senake Perera MC, Saffigna PG (2002) Hydrofluoric acid pre-treatment for improving ${ }^{13} \mathrm{C}$ CPMAS NMR spectral quality of forest soils in south-east Queensland, Australia. Aust J Soil Res 40:655-674

30. Piccolo A, Campanella L, Petronio BN (1990) Carbon-13 nuclear magnetic resonance spectra of soil humic substances extracted by different mechanisms. Soil Sci Soc Am J 54:750-756

31. Stevenson FJ (1982) Humus chemistry: genesis, composition, reactions. Wiley, New York

32. Francioso O, Ciavatta C, Montecchio D, Tugnoli V, Sàncez-Cortés S, Gessa C (2003) Quantitative estimation of peat, brown coal and lignite humic acids using chemical parameters, ${ }^{1} \mathrm{H}-\mathrm{NMR}$. Bioresource Technol 88:189-195

33. van der Marel HW, Beutelspacher H (1976) Atlas of infrared spectroscopy of clay minerals and their admixtures. Elsevier, Amsterdam

34. Madejovà J, Komadel P (2001) Baseline studies of the clay minerals society source clay: infrared methods. Clay Clay Mineral 49:410-432

35. Vinkler P, Lakatos B, Meisel J (1976) Infrared spectroscopic investigation of humic substances and their metal complexes. Geoderma 15:231-242

36. Piccolo A, Stevenson FJ (1982) Infrared spectra of $\mathrm{Cu}^{2+}, \mathrm{Pb}^{2+}$, and $\mathrm{Ca}^{2+}$ complexes of soil humic substances. Geoderma 27:195-208

37. Inoue K, Huang PM (1985) Influence of citric acid on the formation of short-range ordered aluminosilicates. Clay Clay Mineral 33:312-322

38. Inoue K, Huang PM (1990) Perturbation of imogolite formation by humic substances. Soil Sci Soc Am J 54:1490-1497

39. Bartoli F, Philippy R, Portal JM, Gerard B (1992) Poorly ordered Fe oxides, colloidal dispersion and soil aggregation. I. Effect of humic macromolecules on surface and colloidal properties of Fe(III) polycations. J Soil Sci 43:47-58

40. Leone $P$, Nègre $M$, Gennari M, Boero V, Celis R, Cornejo J (2001) Adsorption of imidazolinone herbicides on ferrihydrite-humic acid associations. J Environ Health, Part B 2:127-142 
41. Cornejo J (1987) Porosity evolution of thermally treated hydrous ferric oxide gel. J Colloid Interf Sci 115:260-263

42. Hsu PH (1989) Aluminum hydroxides and oxyhydroxides. In: Dixon JB, Weed SB (eds) Minerals in soil Environments, SSSA Book Series: 1. Soil Science Society of America, Madison, pp 331-378

43. De Cristofaro A, He JZ, Zhou DH, Violante A (2000) Adsorption of phosphate and tartrate on hydroxy-aluminum-oxalate precipitates. Soil Sci Soc Am J 64:1347-1355

44. Watanabe A, Takada $\mathrm{H}$ (2006) Structural stability and natural ${ }^{13} \mathrm{C}$ abundance of humic acids in buried volcanic ash soil. Soil Sci Plant Nutr 52:145-152

45. Tombacz E, Gilde M, Abraham I, Sza'nto' F (1988) Effect of electrolyte concentration on the interaction of humic acid and humate with montmorillonite. Appl Clay Sci 3:31-52

46. Schulthess CP, Huang CP (1991) Humic and fulvic acid adsorption by silicone and aluminium oxide surfaces on clay minerals. Soil Sci Soc Am J 55:34-42

47. Elfarissi F, Pefferkorn M (2000) Kaolinite: humic acid interaction in the presence of aluminium ion. Colloids Surf A 168:1-12

48. Tombacz E, Libor Z, Illes E, Majzik A, Klump E (2004) The role of reactive surface sites and complexation by humic acids in the interaction of clay mineral and iron oxide particles. Org Geochem 35:257-267

49. Nègre M, Leone P, Trichet J, Defarge C, Boero V, Gennari M (2004) Characterization of model soil colloids by cryo-scanning electron microscopy. Geoderma 121:1-16

50. Feng X, Simpson AJ, Simpson M (2005) Chemical and mineralogical controls on humic acid sorption to clay mineral surfaces. Org Geochem 36:1563-1566

51. Wada SI, Wada K (1980) Formation, composition and structure of hydroxyaluminosilicate ions. J Soil Sci 31:457-467

52. Yong R, Mourato ND N (1990) Influence of polysaccharides on kaolinite structure and properties in a kaolinite-water system. Can Geotechnical J 27:774-788

53. Powell HJK, Fenton E (1996) Size fractionation of humic substances: effect on metal binding properties. Anal Chim Acta 334:27-38

54. Klucakova M, Peka M (2008) Behaviour of partially soluble humic acids in aqueous suspensions. Colloids Surf A 318:106-110

55. Christensen JJ, Hansen LD, Izatt RM (1976) Handbook of proton ionization heats and related thermodynamic quantities. Wiley, New York

56. Martell AE, Smith RM (1977) Critical stability constants: Other organic ligands, vol 3. Plenum, New York

57. Terashima M, Fukushima M, Tanaka S (2004) Influence of pH on the surface activity of humic acid: micelle-like aggregate formation and interfacial adsorption. Colloids Surf A 247:77-83

58. Alvarez-Puebla RA, Garrido JJ (2005) Effect of pH on the aggregation of a gray humica acid in colloidal and solid states. Chemosphere 59:659-667

59. Klucakova M, Peka M (2005) Solubility and dissociation of lignitic humic acids in water suspension. Colloids Surf A 252:157-164

doi:10.1186/s40538-014-0009-x

Cite this article as: Baglieri et al:: Chemical and spectroscopic

characterization of insoluble and soluble humic acid fractions at different $\mathrm{pH}$ values. Chemical and Biological Technologies in Agriculture 2014 1:9.

\section{Submit your manuscript to a SpringerOpen ${ }^{\circ}$ journal and benefit from:}

- Convenient online submission

- Rigorous peer review

- Immediate publication on acceptance

- Open access: articles freely available online

- High visibility within the field

- Retaining the copyright to your article

Submit your next manuscript at $\gg$ springeropen.com 